Article

\title{
Comparison of Multi-Control Strategies for the Control of Indoor Air Temperature and $\mathrm{CO}_{2}$ with OpenModelica Modeling
}

\author{
Wei Wang ${ }^{1}$, Xiaofang Shan ${ }^{2, *}$, Syed Asad Hussain ${ }^{3}$, Changshan Wang ${ }^{4}$ and Ying Ji ${ }^{5,6}$ \\ 1 School of Architecture, Southeast University, Sipailou 2\#, Xuanwu District, Nanjing 210096, China; \\ weiwang@seu.edu.cn \\ 2 School of Civil Engineering and Architecture, Wuhan University of Technology, No. 122 Luoshi Road, \\ Wuhan 430070, China \\ 3 Department of Architecture and Civil Engineering, City University of Hong Kong, Tat Chee Avenue, \\ Kowloon, Hong Kong 999077, China; sahussain2@cityu.edu.hk \\ 4 Nanjing Lvzhen Construction Technology Co., Ltd. Building 11, Qinhefang, Chunjiang New Town, \\ Yuhuatai District, Nanjing 210096, China; wangchangshan@csro.cn \\ 5 College of Architecture and Civil Engineering, Beijing University of Technology, Beijing 100124, China; \\ jiying@bjut.edu.cn \\ 6 Beijing Key Laboratory of Green Built Environment and Energy Efficient Technology, Beijing University \\ of Technology, Beijing 100124, China \\ * Correspondence: xfshan@whut.edu.cn
}

Received: 4 August 2020; Accepted: 23 August 2020; Published: 27 August 2020

\begin{abstract}
As most residents spend more than $90 \%$ of their time in buildings, acceptable and reasonable control of both indoor thermal comfort and air quality is imperative to ensure occupants' health status and work productivity. However, current control strategies generally take either thermal comfort or indoor air quality as a single loop, rather than the concurrent control of two. To analyze their mutual influence, this study investigated the performance of three multi-control approaches, i.e., proportional integral derivative (PID) control of thermal comfort and a fixed outdoor air ratio, PID control of thermal comfort and design outdoor air rate, and PID control of thermal comfort and occupancy-based demand-controlled ventilation. As a pilot study, three typical control methods were implemented to a multi-zone building via OpenModelica modeling. The results indicate that indoor air temperature can be well-maintained under three control methods, however, the $\mathrm{CO}_{2}$ concentration under the fixed outdoor air ratio was over $1000 \mathrm{ppm}$, leading to poor indoor air quality. The control strategy with the design outdoor air rate could not properly ensure the $\mathrm{CO}_{2}$ concentration, due to the over-ventilated or under-ventilated phenomena, subsequently resulting in unnecessary energy waste. The occupancy-based demand controlled ventilation could maintain the $\mathrm{CO}_{2}$ concentration under the set-point with an intermediate power energy utilization.
\end{abstract}

Keywords: thermal comfort; indoor air quality; multi-control strategies; energy use; OpenModelica modeling

\section{Introduction}

Among building energy consumers, heat, ventilation, and air conditioning (HVAC) systems dominate more than $40 \%$ of power consumption, to maintain acceptable indoor air quality (IAQ) and thermal comfort (TC) status [1,2]. These two objectives are consistently urgent and essential issues for human health, since most people spend more than $90 \%$ of their time inside buildings [3,4]. A poor IAQ or uncomfortable indoor environment could cause health problems and diseases, as well as 
negatively affect work productivity and occupants' performance $[5,6]$. However, there is always a trade-off between energy consumptions and maintenance of IAQ and TC [7]. Energy-efficient HVAC systems might compromise IAQ and TC, while strict construction of healthy and comfortable indoor environment usually demands more energy consumptions. Thus, the energy-efficient control strategies of IAQ and TC has gained the attention of researchers, to reduce energy consumption without compromising thermal comfort $[8,9]$ and IAQ $[10,11]$, which shows that these energy efficient control strategies have the potential to save $14 \%$ to $34 \%$ of building energy.

\subsection{Control Strategies of TC}

Concerning the air-conditioned space, the cool or heat air supply aims to offset the cooling or heating loads, respectively, to maintain the conditioned space within the desired temperature scope. Too high or too low indoor air temperature might cause uncomfortable thermal sensation to occupants and consequently affect their work efficiency and health status as well $[12,13]$. Typical air conditioning (AC) systems can be categorized into constant air volume (CAV) system, fan-coil (FC) system, and variable air volume (VAV) [14]. The control strategies of indoor air temperature for three kinds of AC systems are different. The CAV system varies the supply of air temperature to match the dynamic cooling/heating loads, to maintain a predetermined indoor air temperature. The FC system maintains a desired indoor air temperature by adjusting the flow rate of chilled water. As for the VAV system, the supply air volume is changed to match the reduction of space load during the partial-load period, to ensure the acceptable indoor air temperature. Compared to the CAV and FC systems, the VAV system has the best energy-efficiency performance that can save a lot of fan power energy, by varying the supply air volumes [14]. In [15], the advancement of control strategies in VAV systems were reviewed. The most common and widely used controllers in the VAV systems are the proportional integral derivative (PID) controllers, as they have the advantages of restricting the control system to the set-point and are easy to realize with a simple structure. Meanwhile, researchers also proposed some optimal and predictive controllers in the VAV systems, e.g., fuzzy prediction PID controller [16], reset of static pressure control [17], air temperature reset control [18], and occupancy-demanded model predictive control (MPC) [19]. Compared to conventional PID controllers, the optimal controllers consider possible future interior and exterior disturbances, but complex and non-linear building models are required for these optimal controllers, which means it is harder to realize and implement this in actual applications [15]. Although many control strategies within VAV systems are proposed, the control objective was just indoor air temperature and thermal comfort, and fewer control strategies concerned ventilation and IAQ.

\subsection{Control Strategies of IAQ}

Besides thermal comfort, IAQ is a critical factor affecting human health. Generally, a livable indoor environment is free from toxic gas, and thus the concentration of carbon dioxide $\left(\mathrm{CO}_{2}\right)$ is a major concern. A high level of $\mathrm{CO}_{2}$ can cause sick building syndromes of occupants, e.g., headache, breath with difficulty, etc. [20]. In most buildings, ventilation is a typical method to improve indoor air quality, and ventilation systems are efficiently equipped to dilute contaminants, improve the indoor environment and decrease the risk of public health problems, by introducing non-polluted outdoor air throughout buildings [21]. The ventilation requirement of the ASHRAE Standard 62.1 [22] prescribes the ventilation rates in two components, one to dilute the contaminants generated by the occupants and the other for building-related sources. While the energy cost is much higher, since outdoor air cooling/heating load constitutes most energy consumption in HVAC systems, some studies show that $30 \%$ or more of the annual cooling/heating energy cost would be consumed, while handling the outdoor air in a typical office building [23]. Energy demand for building ventilation systems forms one of the most important operating factors when maintaining the health level of IAQ of buildings [24]. Therefore, efforts on outdoor air control significantly focus on indoor air quality and building energy consumption. Moreover, demand-controlled ventilation is a method validated in controlling outdoor airflow to 
achieve the proper balance between IAQ and energy saving. In [25], a dynamic demanded-controlled ventilation strategy of $\mathrm{CO}_{2}$ control was applied to an hourly scheduled sports training center, by setting a base ventilation rate for unoccupied periods and calculating the ventilation rate dynamically at each occupied period. The results showed that the strategy could save $34 \%$ of energy related to ventilation air as compared to proportional control. Except for adjusting ventilation rate, an alternative control strategy of supply air $\mathrm{CO}_{2}$ concentration could also achieve $\mathrm{CO}_{2}$ control. In [26], a supply $\mathrm{CO}_{2}$-based, demand-controlled ventilation strategy was proposed by determining the $\mathrm{CO}_{2}$ concentration of supply air to meet the IAQ requirement of the critical zone, which showed that such a control strategy could maintain good IAQ with $3.1 \%$ annual energy saving. While the supply $\mathrm{CO}_{2}$-based, demand-controlled method was based on the design occupancy profile rather than the real occupancy, when analyzing the $\mathrm{CO}_{2}$ levels, researchers assumed the supply air rate was constant, without considering the changes of indoor air temperature, which was not in accordance with the actual situation. In the authors' previous work [27], the occupancy-based DCV (demand-controlled ventilation) strategy was proposed and applied to a multi-zone building, to optimize indoor air quality. However, when coordinating the ventilation rate for multi zones, the supply air rate and indoor air temperature were predetermined without consideration of the variation of indoor air temperature.

Through the above statement, we note that the current control strategies of indoor air temperature and $\mathrm{CO}_{2}$ are independently performed, without considering the mutual influence between indoor air temperature control and $\mathrm{CO}_{2}$ control. In fact, the indoor air temperature control in VAV systems could result in the change of outdoor air rate and affect the $\mathrm{CO}_{2}$ concentration levels for multi-zone buildings. Conversely, the $\mathrm{CO}_{2}$ control might also have certain effects on supply air rate and indoor air temperature. In this study, the multi-control strategies of indoor air temperature and $\mathrm{CO}_{2}$ were investigated with OpenModelica simulation, by simultaneously analyzing the changing patterns of indoor air temperature and $\mathrm{CO}_{2}$ concentration, for a multi-zone building with VAV systems. The control performance of three typical multi-control strategies, i.e., PID control of thermal comfort and a fixed outdoor air ratio, PID control of thermal comfort and design outdoor air rate, PID control of thermal comfort and occupancy-based demand-controlled ventilation, were compared via the OpenModelica modeling. With the predicted occupancy profiles, the performance of occupancy-based, multi-control strategy for indoor air temperature and $\mathrm{CO}_{2}$ were evaluated as well. Finally, the energy usage of three multi-control strategies was also analyzed.

\section{Background}

\subsection{Principles of Indoor Air Temperature Control and $\mathrm{CO}_{2}$ Control}

As defined in the ASHRAE standard 55 [28], indoor air temperature should range within the thermal comfort zone to ensure people's thermal comfort status. If the indoor air temperature is too high, some occupants might feel hot, while if the temperature is too low, some occupants might feel cold. Indoor air temperature is the key factor that affects thermal sensations of occupants. Meanwhile, indoor air temperature is influenced both by internal and external parameters, e.g., supply air conditions, outdoor air temperature, the number of occupants, etc. For an air-conditioned thermal zone, the heat balance of the indoor environment can be expressed as Equation (1):

$$
C_{a} \rho V_{z} \frac{d T_{z}}{d_{t}}=C_{a} \rho V_{s z}\left(T_{s}-T_{z}\right)+Q_{\text {load }}
$$

where $T_{z}$ is the indoor air temperature of the conditioned zone, $\mathrm{K} ; V_{z}$ is the volume of the conditioned zone, $\mathrm{m}^{3} ; \rho$ is the air mass density, $\mathrm{kg} / \mathrm{m}^{3} ; C_{a}$ is the specific heat of air (at constant pressure), $\mathrm{J} /(\mathrm{kg} \cdot \mathrm{K}$ ); $V_{s z}$ is the supply air rate for the conditioned zone, $\mathrm{m}^{3} ; T_{S}$ is the supply air temperature, $\mathrm{K}$; and $Q_{\text {load }}$ is the cooling load of the conditioned space, $\mathrm{W}$.

As the cooling load varied with the outdoor conditions (i.e., outdoor air temperature) and the internal loads (i.e., occupants, electric devices), the supply air rate or supply air temperature could 
be adjusted to ensure the heat balance of indoor environment and control indoor air temperature. According to different control variables, thermal comfort control strategies could be divided into variable volume control (VAV) and variable temperature control [29]. The premier control method aims to maintain the heat balance by changing the volume of supply air with constant supply air temperature. The other control method (i.e., variable temperature control) tries to change supply air temperature to ensure the heat balance of the indoor environment. Compared to variable temperature control, VAV control is more widely implemented in practical applications, as it is easy to realize [30].

Beside thermal comfort, there is a growing concern about the need to improve the indoor air quality of buildings and reduce the associated ventilation energy consumption. As for the air-conditioned space, the indoor pollutant mainly concerns carbon dioxide generated by occupants' respiration. The mass balance of $\mathrm{CO}_{2}$ in the ventilation space can be expressed as below:

$$
V_{\text {out }} C_{o}+m_{e}-V_{\text {out }} C_{z}=V \frac{d C_{z}}{d \tau}
$$

where $V_{\text {out }}$ is the outdoor air rate, $\mathrm{m}^{3} / \mathrm{s} ; \mathrm{C}_{0}$ is the outdoor air $\mathrm{CO}_{2}$ concentration that can be regarded as constant, $\mathrm{g} / \mathrm{m}^{3} ; m_{e}$ is the indoor $\mathrm{CO}_{2}$ generation rate, $\mathrm{g} / \mathrm{s} ; \mathrm{C}_{z}$ is the $\mathrm{CO}_{2}$ concentration of the ventilation zone, $\mathrm{g} / \mathrm{m}^{3}$; and $V$ is the volume of the ventilation zone, $\mathrm{m}^{3}$.

Based on Equation (2), the $\mathrm{CO}_{2}$ concentration level of the zone is affected by the outdoor air rate and the $\mathrm{CO}_{2}$ generation rate of the zone. At the same time, the $\mathrm{CO}_{2}$ generation rate is related to the number of occupants inside the zone. According to the ASHRAE standard 62.1-2019 [22], the outdoor air rate can be determined by the occupancy and required outdoor air rate for each person. Consequently, the proper determination of outdoor air rate is the key to maintain indoor air quality.

\subsection{Multi-Control of Indoor Air Temperature and $\mathrm{CO}_{2}$}

The multiple control of thermal comfort and indoor air quality can be easily implemented for a single room or single-zone buildings, which could be achieved by controlling the supply air rate and outdoor air rate, respectively, according to the thermostat and $\mathrm{CO}_{2}$ sensor. However, as for multi-zone buildings, the building shares only one air handling unit (AHU) to provide fresh air and cool air to different thermal zones, to concurrently ensure the thermal comfort and indoor air quality, as shown in Figure 1 [31].

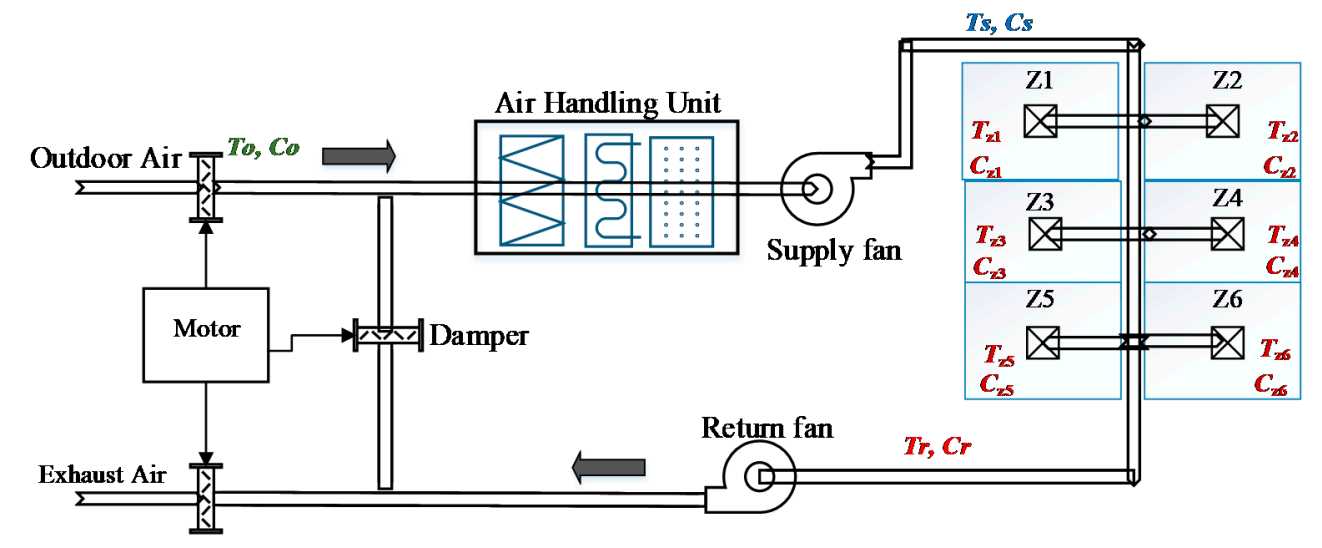

Figure 1. The framework of the air conditioning system for multi-zone buildings.

In general, by installing the VAV boxes at each zone, the indoor air temperature could be effectively maintained by changing the supply air volume. As is known, the indoor air quality is heavily dependent on the outdoor air rate. Considering the AC system scheme, all return air from different thermal zones is mixed in the return duct, as expressed by Equation (3): 


$$
C_{r}=\frac{\sum_{i} V_{s a, i} C_{z, i}}{\sum_{i} V_{s a, i}}=\frac{\sum_{i} V_{s a, i} C_{z, i}}{V_{s a, t o t}}
$$

where $C_{r}$ represents the $\mathrm{CO}_{2}$ concentration at the return duct; $V_{s a, i}$ is the supply air rate for zone $i$; $\mathrm{C}_{z, i}$ is the $\mathrm{CO}_{2}$ concentration of zone $\mathrm{i} ; V_{s a \text {,tot }}$ is the total supply air rate of the system. The $\mathrm{CO}_{2}$-based demand-controlled ventilation is one of the strategies that could lower ventilation energy use by reducing over-ventilation of the multi-zone buildings. With the $\mathrm{CO}_{2}$-based DCV strategy, the outdoor air rate is determined by the $\mathrm{CO}_{2}$ concentration level at the return duct. However, according to Equation (3), the $\mathrm{CO}_{2}$ concentration level at the return duct cannot accurately reveal the $\mathrm{CO}_{2}$ concentration of multiple thermal zones. Such a controlling approach cannot effectively ensure the indoor air quality, as it might result in poor indoor air quality in certain zones of multi-zone buildings. Therefore, the outdoor air rate needs to be carefully determined to ensure acceptable indoor air quality of different thermal zones, with fewer energy consumptions.

\subsection{OpenModelica Modeling}

Modelica is an equation-based, object-oriented language, which was developed to model complex engineering systems that were described by coupled systems of differential, algebraic, and discrete equations [32]. By using the Modelica prototyping, OpenModelica is an open-source Modelica-based simulation platform, which is robust to dynamic modeling for complex systems, consisting of multi-domains [33]. Different from conventional modeling and simulation programs, Modelica-based simulation program has the advantages of addressing acausal modeling, which can be determined by users [34]. With OpenModelica platform, a large class of library packages for thermo-fluid systems can be implemented for simulating HVAC equipment, e.g., ThermoFlow Library, AirConditioning Library, and Modelica_Fluid Library [35]. For building energy and control systems, the Building Library, developed by the Lawrence Berkeley National Laboratory, is a free and open-source Modelica Library that consists of thermal and fluid domains of the HVAC systems and the typical control strategies [36,37]. Meanwhile, the library supports building envelope and multi-zone simulations. In our study, the simulation platform OpenModelica with Building Library was used to simulate the performance of HVAC systems.

\section{Methodology and Case Study}

Through the statement of control methods of thermal comfort and indoor air quality, it was justified to combine typical control techniques to investigate the changing laws of indoor air temperature and $\mathrm{CO}_{2}$ concentration. In this study, three different combined control strategies were assessed.

\subsection{Multi-Control Strategies for the Control of Indoor Air Temperaure and $\mathrm{CO}_{2}$}

\subsubsection{Strategy 1: PID Control for Indoor Air Temperature and Fixed Minimum Outdoor Air Fraction}

The indoor air temperature was maintained by adjusting the supply air rate of the air handling unit. A VAV (variable air volume) box was installed at each zone to control the volume of cool air supplied to the zone, so the supply air rate would be dynamically changed to offset the variable cooling loads. Through PID control of the damper position, the supply air rate varied from the minimum to maximum volume, to maintain the indoor air temperature. The relationship between indoor air temperature and supply air rate could be determined by Equation (1).

As for the indoor air quality, the outdoor air was provided to dilute the indoor contaminants. Inside air-conditioned buildings, $\mathrm{CO}_{2}$ is the main contaminant generated by occupants and other sources. Outdoor air with a lower $\mathrm{CO}_{2}$ concentration level is supplied to buildings to ensure indoor air quality. The outdoor air rate could be determined by the ratio to supply airflow rate, as shown in Equation (4): 


$$
Y_{s 1}=\frac{V_{o t}}{V_{s t}}=\text { const }
$$

Generally, the minimum outdoor air ratio ranges from $15 \%$ to $30 \%$. In this study, the outdoor air fraction was fixed as $25 \%$. Thus, the outdoor air rate could be determined by the supply airflow rate.

\subsubsection{Strategy 2: PID Control for Indoor Air Temperature and Fixed Outdoor Air Rate}

The indoor air temperature was also controlled by a VAV box, by changing the supply air volumes. According to the ASHRAE standard 62.1 [22], the required outdoor airflow rate was determined by accounting for people-related sources and area-related sources, as shown in Equation (5):

$$
V_{o z}=R_{p} \times P_{z}+R_{a} \times A_{z}
$$

where $R_{p}$ represents the outdoor airflow rate per person to dilute contaminants generated by people, $\mathrm{L} / \mathrm{s}$.per; $R_{a}$ is the outdoor airflow rate per unit area to dilute contaminants emitted by floor area, $\mathrm{L} / \mathrm{s} \cdot \mathrm{m}^{2}$; $P_{z}$ is the designed zone population; $A_{z}$ is the floor area of the zone, $\mathrm{m}^{2}$. The values of $R_{p}$ and $R_{a}$ are related to the building types.

The uncorrected outdoor airflow rate for the multi-zone buildings are shown in Equation (6):

$$
V_{\text {ou }}=\sum_{i=1} R_{p} \times P_{z, i}+\sum_{i=1} R_{a} \times A_{z, i}
$$

where $V_{o u}$ is the uncorrected outdoor airflow rate of the system, $\mathrm{m}^{3} / \mathrm{s}$.

The outdoor air ratio of the system was determined by Equation (7):

$$
Y_{s 2}=\frac{V_{o u}}{V_{s t}}=\frac{\sum_{i=1} R_{p} \times P_{z, i}+\sum_{i=1} R_{a} \times A_{z, i}}{V_{s t}}
$$

\subsubsection{Strategy 3: PID Control for Indoor Air Temperature and Demand-Controlled Outdoor Air Rate}

The indoor air temperature of the system was also controlled by changing the supply air volume of the VAV boxes. As for the indoor air quality, if the occupancy profile of the different thermal zones could be predicted, the required outdoor air rate of the zone could be determined, based on Equation (5). Within Strategy 2, the outdoor air rate was determined by the design number of occupants, since the accurate occupancy profile could not be obtained. If the occupancy profile of thermal zones could be well predicted, the outdoor air rate would dynamically change with the predicted occupancy. For Strategy 3, the ventilation scheme was demand-controlled ventilation with the Wi-Fi probe enabled occupancy, to avoid possible over-ventilated or under-ventilated cases. The required outdoor airflow rate of the zone could be determined by Equation (8):

$$
V_{o z}=R_{p} \times P_{p r e, z}^{\tau}+R_{a} \times A_{z}
$$

where $P_{\text {pre, }}{ }^{\tau}$ represents the occupants predicted by the Wi-Fi probe at time $\tau$.

As the occupancy profile is known, by comparing the predicted number of occupants of each zone, the zone requiring the largest outdoor air rate would be selected as the critical zone, as expressed by Equation (9):

$$
\text { Critical Zone }: Z_{\text {cri }}=\max \left\{\frac{V_{o z, i} i^{\tau}}{V_{s z, i} \tau^{\tau}}\right\}
$$

where $V_{o z, i}{ }^{\tau}$ is the required outdoor air rate of zone $i$ at time $\tau$.

Different from Strategy 2, $P_{p r e, z}$ is the predicted number of occupants rather than the design number of occupants of the zone, and thus the required outdoor air rate was no more constant, but dynamically varied with time. According to the multi-zone ventilation method [22], the outdoor air ratio with predicted occupancy profile could be expressed as: 


$$
Y_{s 3}=\frac{\frac{\sum_{i=1} R_{p} \times P_{p r e, z, i}{ }^{\tau}+\sum_{i=1} R_{a} \times A_{z, i}}{V_{s t}}}{1+\frac{\sum_{i=1} R_{p} \times P_{p r e, z, i}{ }^{\tau}+\sum_{i=1} R_{a} \times A_{z, i}}{V_{s t}}-Z_{c r i}}
$$

\subsection{Case Study}

To investigate the performance of control methods on thermal comfort and indoor air quality, three scenarios using different control strategies were studied via the OpenModelica platform. As the real occupancy profiles were difficult to collect, it made the demand-controlled strategy hard to comply with the actual demand of supply air volume and ventilation rate. As mentioned in [38], arobust occupancy prediction method with the Markov time-window inference approach (DMTWI) was proposed. In Strategy 3, the Wi-Fi-probe-enabled occupancy profile was used to determine the outdoor air ratio for ventilation. The occupancy profiles for the office rooms were predicted by the Wi-Fi-probe-based DMTWI, and the predicted occupancy was over $80 \%$, compared to the actual occupancy on-site experiment. The details of the occupancy prediction method are given in previous studies [27,38]. This study mainly focuses on the performance of the occupancy-driven multi-control strategy.

- Scenario 1: PID control of indoor air temperature and fixed outdoor air ratio to dilute $\mathrm{CO}_{2}$ contaminant.

- Scenario 2: PID controls of indoor air temperature and design outdoor air rate to dilute $\mathrm{CO}_{2}$ contaminant.

- Scenario 3: PID controls of indoor air temperature and demanded-control ventilation scheme to dilute $\mathrm{CO}_{2}$ contaminant with Wi-Fi probe enabled occupancy.

The performance of three scenarios was compared via the OpenModelica platform, and the OpenModelica models are shown in Figure 2. The OpenModelica modeling predicted indoor air temperature, $\mathrm{CO}_{2}$ concentration, and supply air rate, under three scenarios. Based on the simulation results, thermal comfort, indoor air quality, and power consumption were compared among the three scenarios. The building model had six similar thermal zones of $10 \mathrm{~m} \times 10 \mathrm{~m} \times 3 \mathrm{~m}$. The supply air temperature was assumed to be $18{ }^{\circ} \mathrm{C}$. The outdoor air $\mathrm{CO}_{2}$ concentration was assumed to be 350 ppm, and the $\mathrm{CO}_{2}$ generation rate of a person kept constant at $4.9 \times 10^{-6} \mathrm{~m}^{3} / \mathrm{s}$. Based on the ASHRAE standard 62.1 for the office building, the outdoor air required rate per person was $3.0 \times 10^{-3} \mathrm{~m}^{3} / \mathrm{s}$, and the area per unit was $0.28 \times 10^{-4} \mathrm{~m}^{3} / \mathrm{s}$. The set-points of indoor air temperature and $\mathrm{CO} 2$ concentrations were $24^{\circ} \mathrm{C}$ and $1000 \mathrm{ppm}$, respectively. The simulation period started from 8:30 am to 18:00. The initial $\mathrm{CO}_{2}$ concentration level and indoor air temperature of all zones were set as $1000 \mathrm{ppm}$ and $27^{\circ} \mathrm{C}$, respectively.

To simplify the control loop, this study made some assumptions, such as:

1. The indoor air temperature and $\mathrm{CO}_{2}$ concentration were uniformly distributed inside the room;

2. We assumed there were no natural ventilation of all rooms with good air tightness;

3. The heat transfer through the building envelope were ignored, and heat gains for all zones were assumed to come from occupants, lights, and computers;

Under the first two scenarios, two kinds of occupancy profiles were assessed, i.e., the designed occupancy recommended by the ASHRAE standards and the real occupancy profile. As for Scenario 3, the Wi-Fi-probe-enabled occupancy and the real occupancy were compared. Thus, six cases were investigated within OpenModelica to evaluate the control effects via the indoor air temperature, $\mathrm{CO}_{2}$ concentration levels, and the power energy consumptions. The indoor air temperature and $\mathrm{CO}_{2}$ concentration level of the rooms were initially set as $27^{\circ} \mathrm{C}$ and $1000 \mathrm{ppm}$, respectively. The air temperature and $\mathrm{CO}_{2}$ concentration of fresh air were $30^{\circ} \mathrm{C}$ and $350 \mathrm{ppm}$, respectively. 


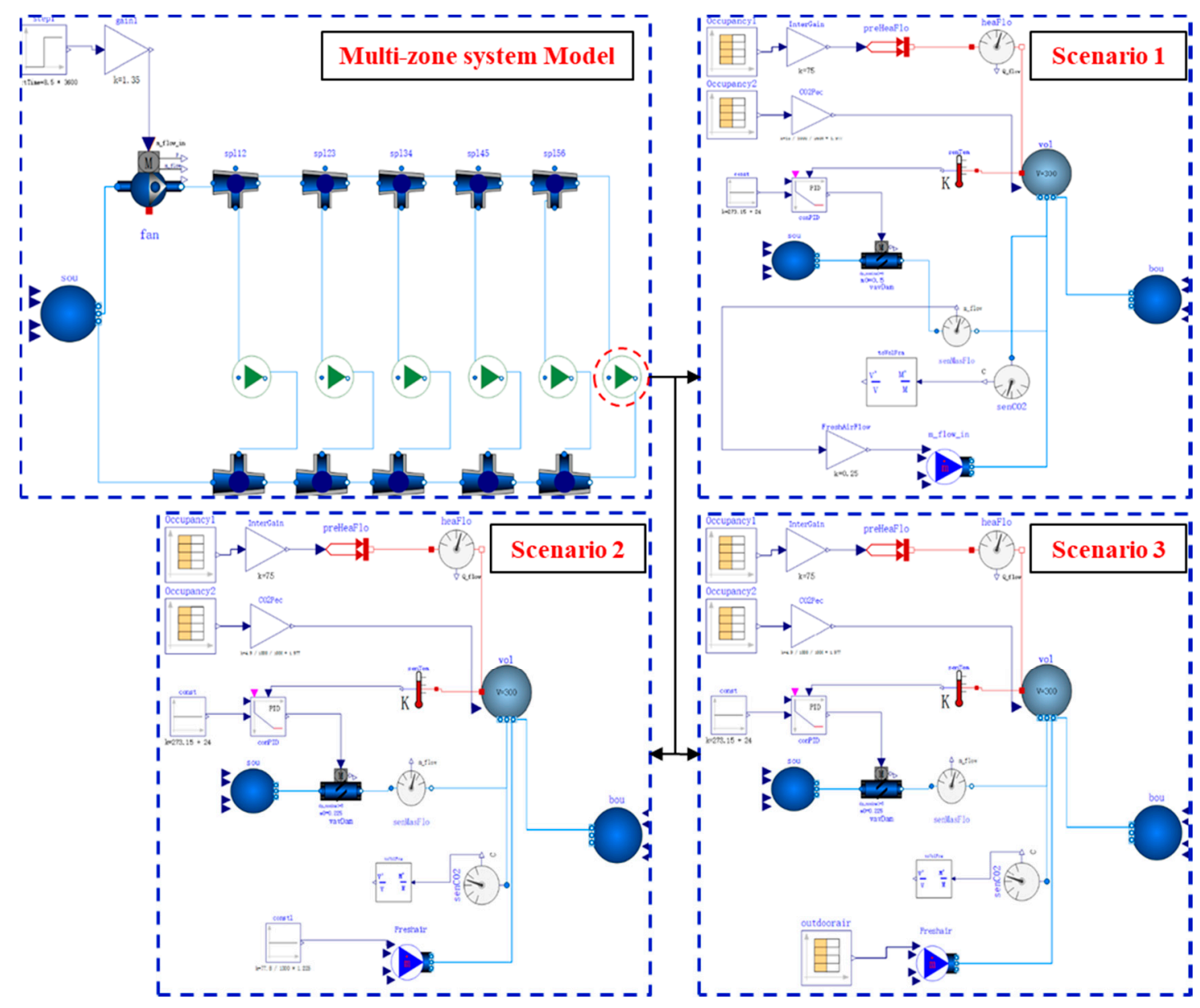

(a)

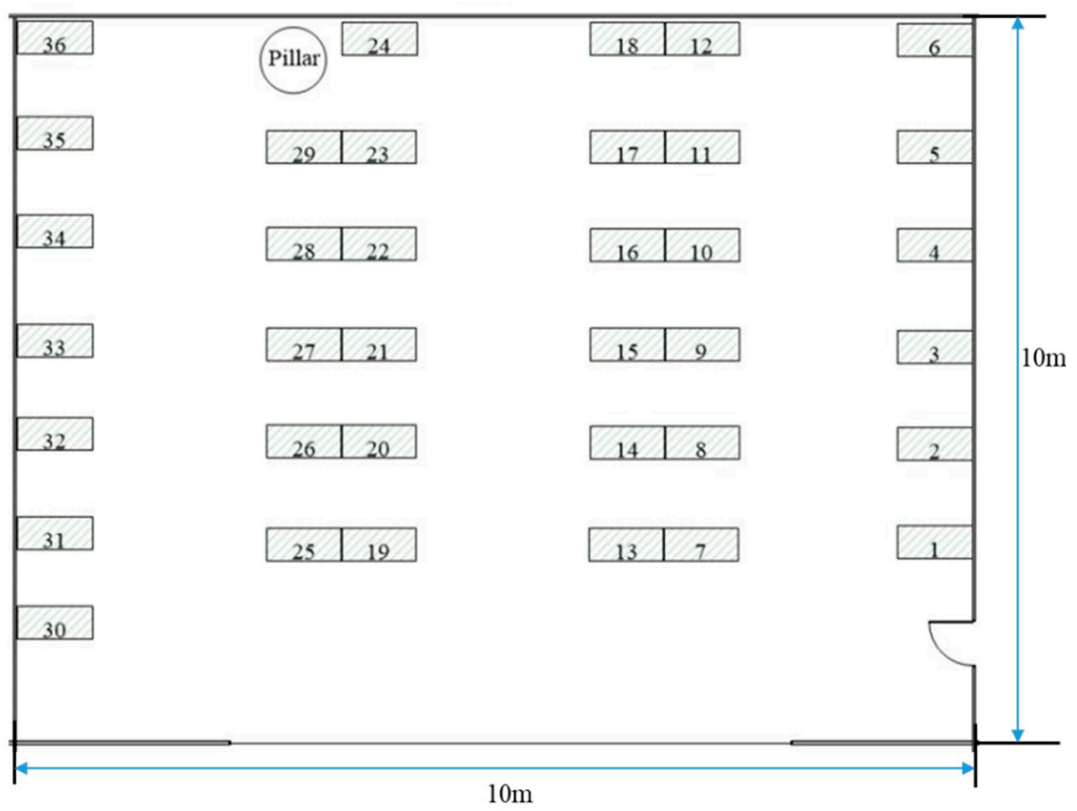

(b)

Figure 2. (a) Multi-control strategies in the OpenModelica models of different scenarios; (b) Geometry of office rooms in the multi-zone building. 


\section{Results of Multi-Control Strategies}

\subsection{Scenario 1: PID Control of Thermal Comfort and Fixed Outdoor Air Ratio}

Under Scenario 1, the control methods for thermal comfort and indoor air quality were PID control and fixed outdoor air fraction, respectively. The outdoor air ratio was fixed as $25 \%$ to the supply air volume. The performance of the control method was simulated with OpenModelica. The $\mathrm{CO}_{2}$ concentration level, indoor air temperature, and supply air rate of six zones were investigated through OpenModelica modeling.

The $\mathrm{CO}_{2}$ concentration levels of the six zones are shown in Figure 3. With the fixed fresh air ratio, the changing laws of $\mathrm{CO}_{2}$ concentration for six zones were similar and complied with exponential changing. At the beginning of the operation time, the $\mathrm{CO}_{2}$ concentration increased from $940 \mathrm{ppm}$ to $1280 \mathrm{ppm}$. After 12:00, the $\mathrm{CO}_{2}$ concentration tended to be stable at $1280 \mathrm{ppm}$. Such a control method of outdoor air rate could not efficiently dilute the $\mathrm{CO}_{2}$ produced by occupants, resulting in poor indoor air quality.

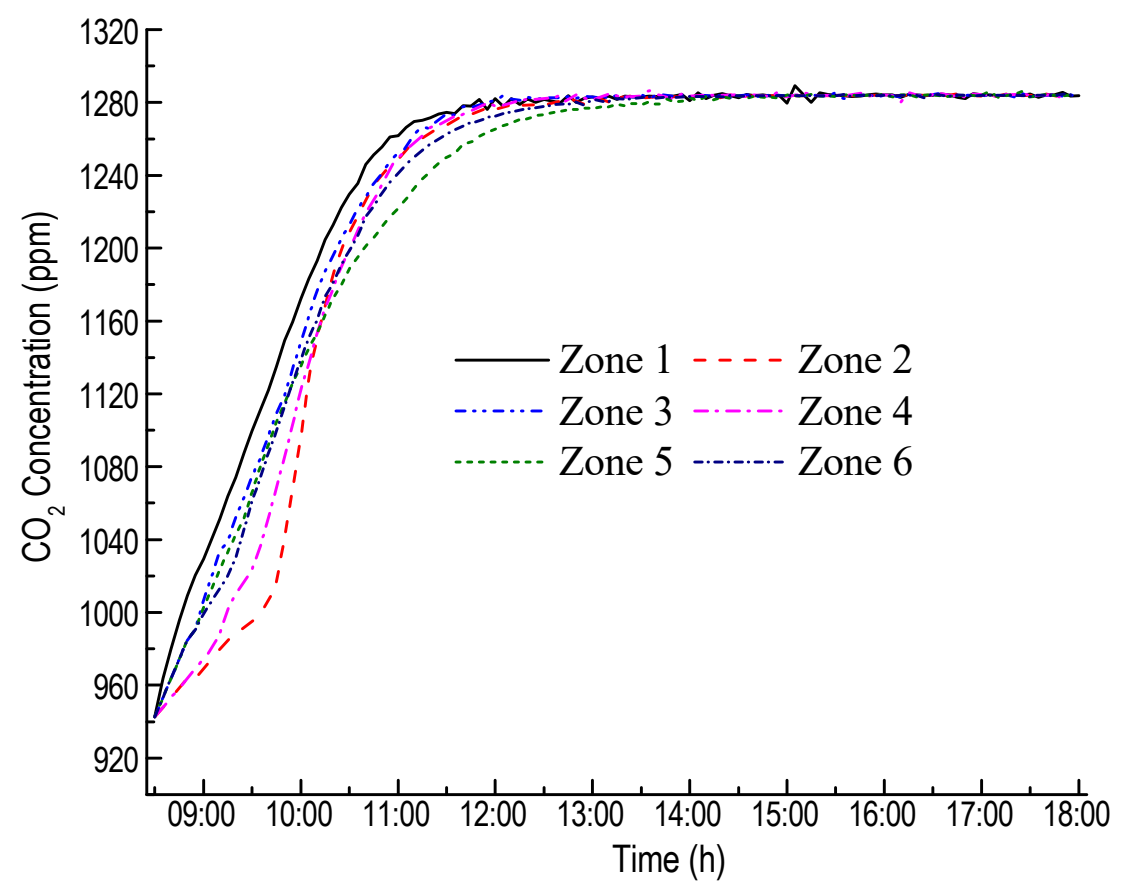

Figure 3. The $\mathrm{CO}_{2}$ concentration levels under Scenario 1.

Besides the indoor air quality, the indoor air temperature under PID control was simulated, as shown in Figure 4. During the operation period, the values of indoor air temperature had small variations around the set-point of indoor air temperature (i.e., $T_{\text {set }}=24^{\circ} \mathrm{C}$ ). The largest discrepancy ranged from $-0.5{ }^{\circ} \mathrm{C}$ to $0.1{ }^{\circ} \mathrm{C}$. The indoor air temperature rose from $23.5^{\circ} \mathrm{C}$ to $24{ }^{\circ} \mathrm{C}$ during the first four operation period with few occupants inside the building. After 10:00 am, the indoor air temperature was well-maintained around $24^{\circ} \mathrm{C}$. Therefore, the PID control of indoor air temperature could effectively ensure an acceptable thermal environment for occupants by controlling supply air volumes. 

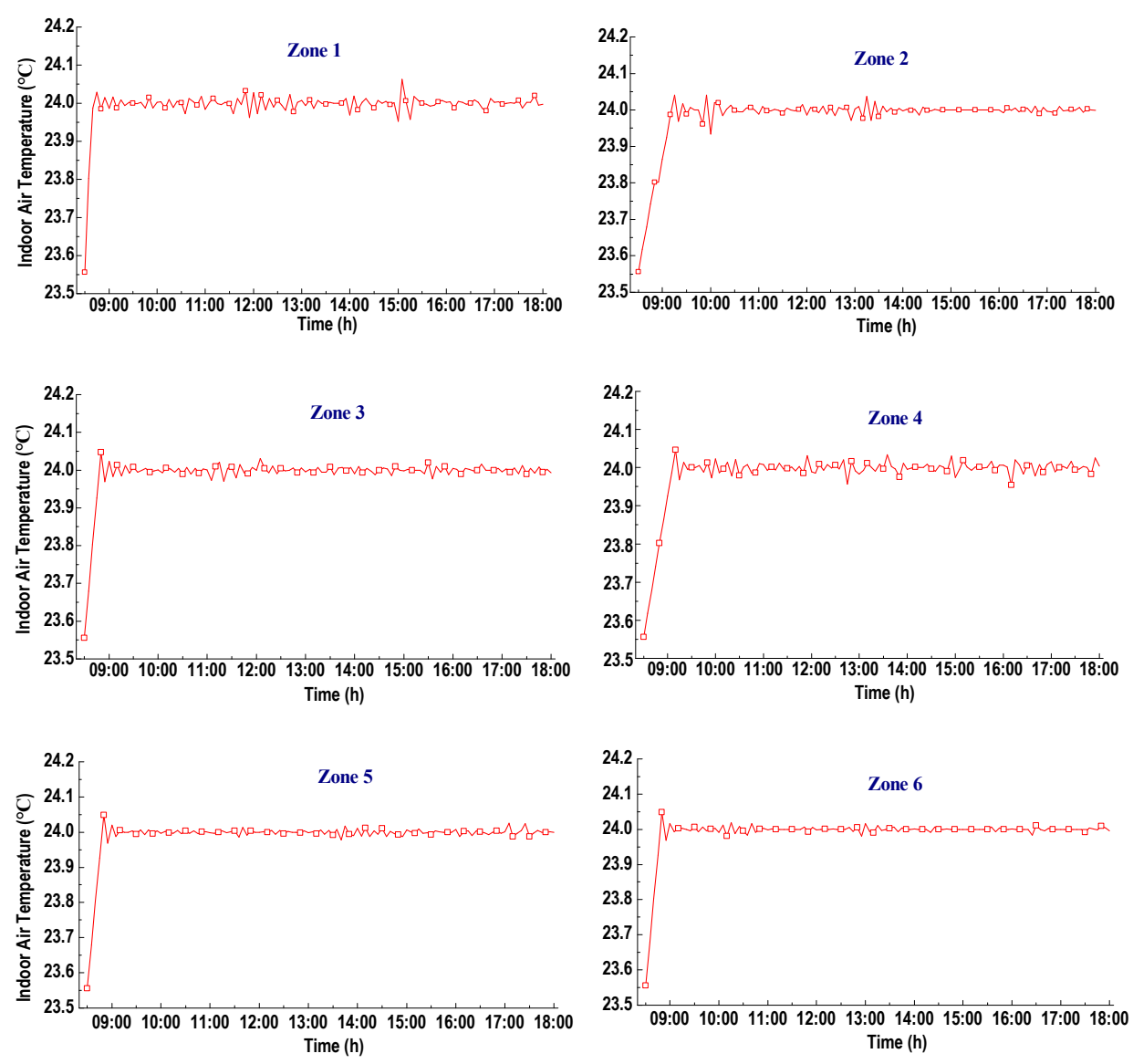

Figure 4. The indoor air temperature of six zones under Scenario 1.

Under Scenario 1, the changing patterns of supply air rate of the six zones were analyzed. As shown in Figure 5, the supply air rate dynamically varied with time during the operation period. Due to the different number of occupants in each zone, the supply air rate was subsequently different. The supply air volumes of Zone 1 and Zone 4 were higher than the other four zones. By assessing the changing curves in Figure 5, it could be summarized that the supply air rate showed an increase at the beginning, as the occupants started entering the building. Then, the supply air volumes decreased as fewer people stayed in the office at lunchtime. In the afternoon, the overall supply air volumes kept stable. After 17:00, the supply air rate decreased, since the occupants gradually left the office. Therefore, the changing patterns of supply air rate complied with the occupancy profile, to maintain indoor air temperature.

The supply air volume and outdoor air rate of the system are calculated, as shown in Figure 6. The changing patterns of the supply air rate and the outdoor air rate were similar, due to the constant outdoor air ratio of 0.25 . The maximum supply air rate was $1.0 \mathrm{~m}^{3} / \mathrm{s}$ at 15:00. 

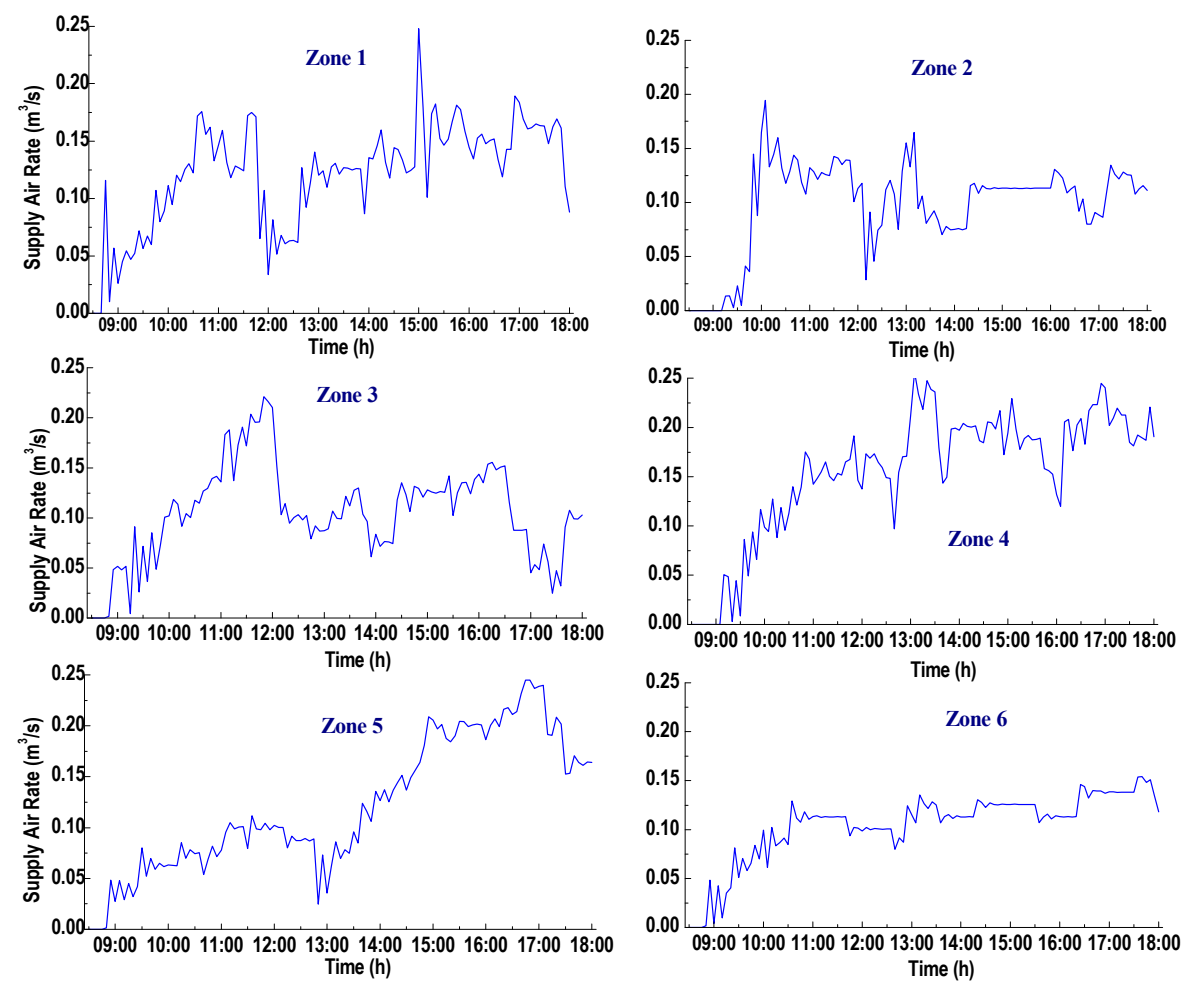

Figure 5. Supply air rate of six zones under Scenario 1.

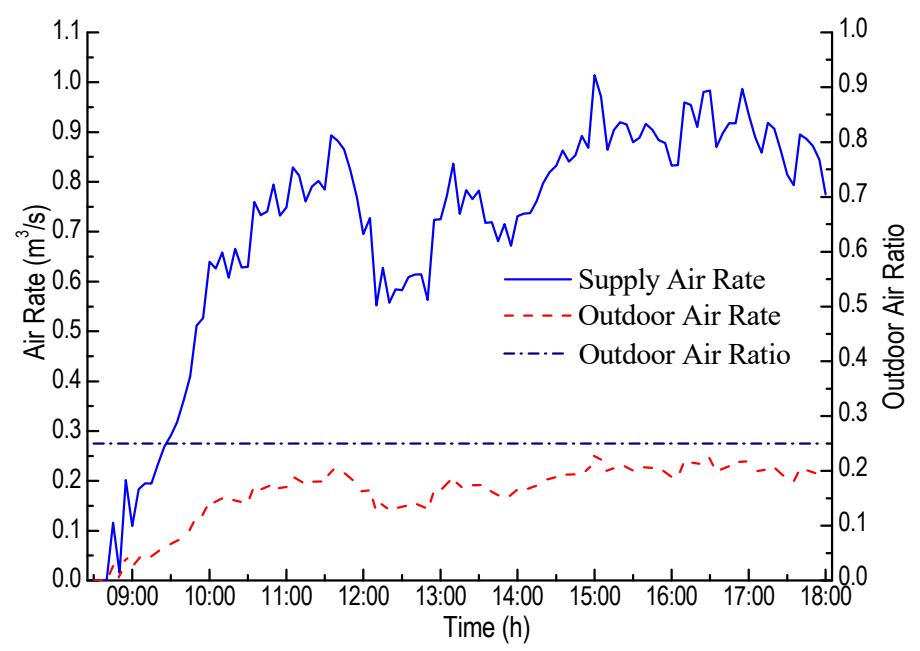

Figure 6. Supply air rate, outdoor air rate, and outdoor air ratio under Scenario 1.

\subsection{Scenario 2: PID Control of Thermal Comfort and Design Outdoor Air Rate}

Under Scenario 2, the PID control was used to maintain thermal comfort, while the multi-zone ventilation method was applied to dilute $\mathrm{CO}_{2}$ generated by occupants. Generally, the real occupancy profile of the thermal zones is unknown. Strategy 2 provides the method to calculate the outdoor airflow rate, expressed as Equation (5), and the required outdoor airflow rate was determined by the design number of the occupants of the zone. Therefore, the outdoor airflow was maintained constant during the operation period.

Through OpenModelica modeling, the $\mathrm{CO}_{2}$ concentration of the six zones under the ventilation scheme of Strategy 2 was predicted, as shown in Figure 7. The figure presents the $\mathrm{CO}_{2}$ concentration level of six thermal zones, which first increased with the number of occupants from 8:30 to 11:00. During this period, as there were fewer occupants than the design occupancy, the $\mathrm{CO}_{2}$ concentration 
of the six zones rose from $350 \mathrm{ppm}$ to $1000 \mathrm{ppm}$. When the real number of occupants was larger than the design number, the $\mathrm{CO}_{2}$ concentration level was over the set-point (i.e., $1000 \mathrm{ppm}$ ). Taking Zone 4 and 5 as an example, the $\mathrm{CO}_{2}$ concentration levels were higher than the set-point from 14:30 to 18:00. At the beginning of the working period, the $\mathrm{CO}_{2}$ concentration of the six zones was much lower than $1000 \mathrm{ppm}$, indicating over ventilation. While under ventilation occurred as the real number of occupants increased beyond the design number. The ventilation scheme with fixed outdoor air rate could not properly ensure $\mathrm{CO}_{2}$ concentration during the operation period, due to the ventilation scheme with the potential to cause over-ventilated or under-ventilated cases.

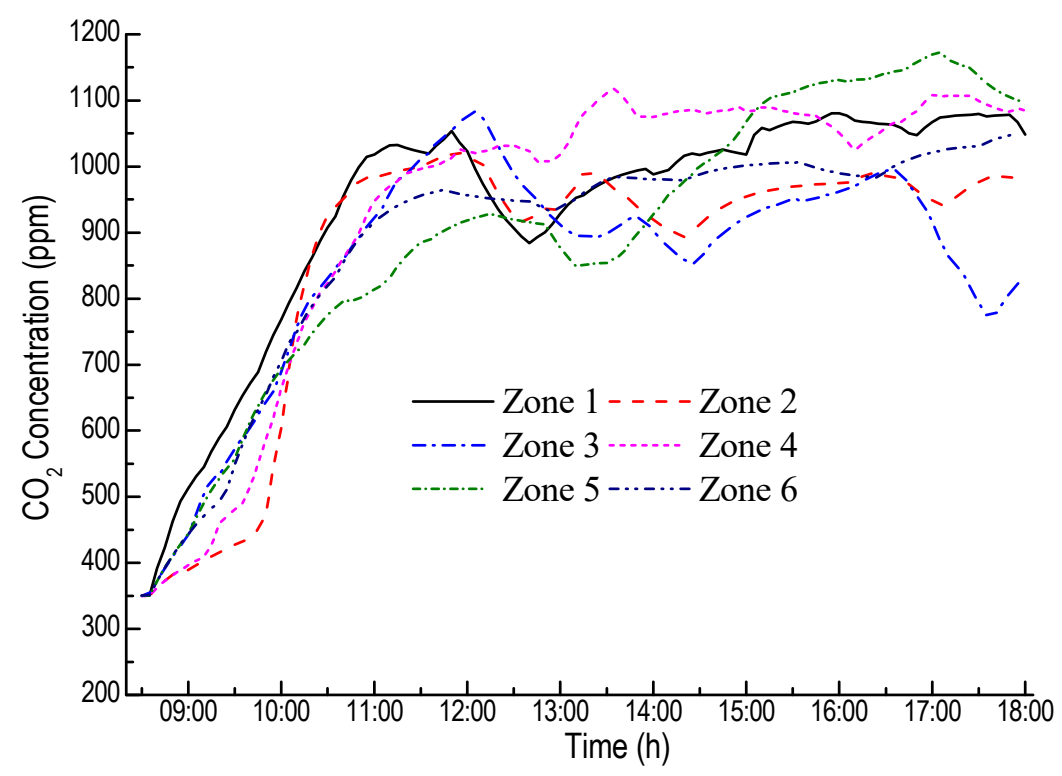

Figure 7. The $\mathrm{CO}_{2}$ concentration of six zones under Scenario 2.

The indoor air temperature was also analyzed via OpenModelica modeling. As illustrated in Figure 8, the indoor air temperature had a small variation around the set-point of indoor air temperature (i.e., $T_{\text {set }}=24^{\circ} \mathrm{C}$ ). The largest discrepancy between indoor air temperature and the set-point varied from $-0.05^{\circ} \mathrm{C}$ to $0.1^{\circ} \mathrm{C}$. Thus, the indoor air temperature could be effectively controlled to maintain the thermal comfort of occupants by changing the supply air rate.

Meanwhile, the supply air rate of six zones was evaluated, as shown in Figure 9. The figure presents the changing patterns of the supply air rate of the six zones. Due to the dynamic occupancy profile, the supply air rate of each zone varied with time, during the working period. By analyzing the changing patterns of the supply air rate of the six zones, it could be concluded that from 8:30 to 11:00, the supply air rate gradually increased from the minimum value (the required ventilation rate) as the occupancy of the zone changed from the unloaded state to the partially loaded state. During the afternoon, the supply air volume reached the maximum value with fully loaded occupants.

The total supply air rate and outdoor air rate of the air conditioning system were analyzed, as shown in Figure 10. Under Scenario 2, the total outdoor air rate of the system was constant, as the outdoor air rate of each zone was determined under the design number of occupants. While the total supply air rate of the system varied with time, and the maximum supply air rate was $1.3 \mathrm{~m}^{3} / \mathrm{s}$, occurring at 15:00. At the beginning of the operation period, with a fixed outdoor air rate, the phenomenon of over ventilation appeared, as the real number of occupants was much smaller than the design value. Figure 7 also reflects over ventilation, as the $\mathrm{CO}_{2}$ concentration levels of the six thermal zones ranged from $350 \mathrm{ppm}$ to $500 \mathrm{ppm}$ between 8:30 to 9:30. Therefore, the fixed outdoor air rate would cause over-ventilation at the beginning of the operation period, which might cause unnecessary wastage of power energy. 


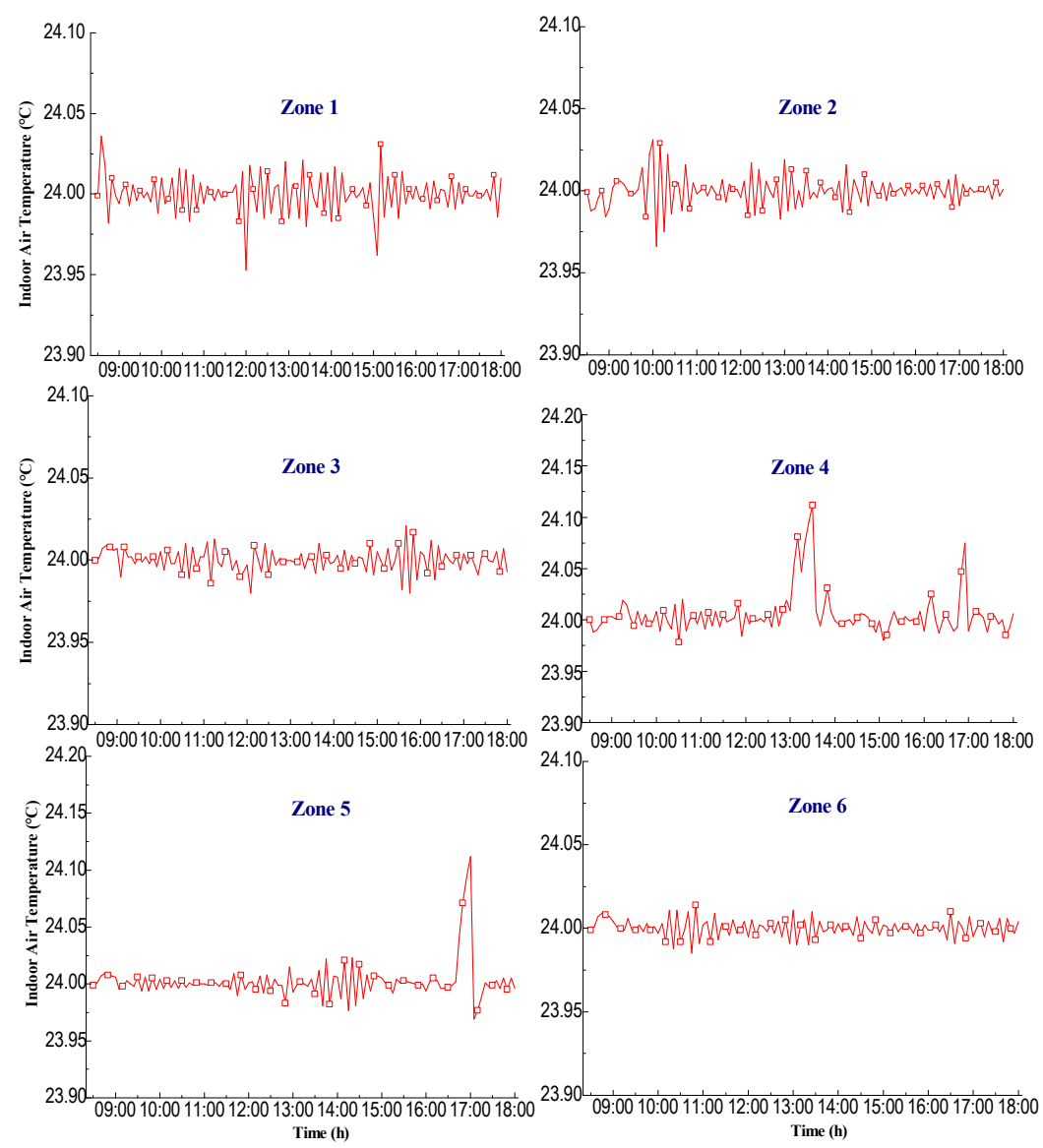

Figure 8. The indoor air temperature of six zones under Scenario 2.
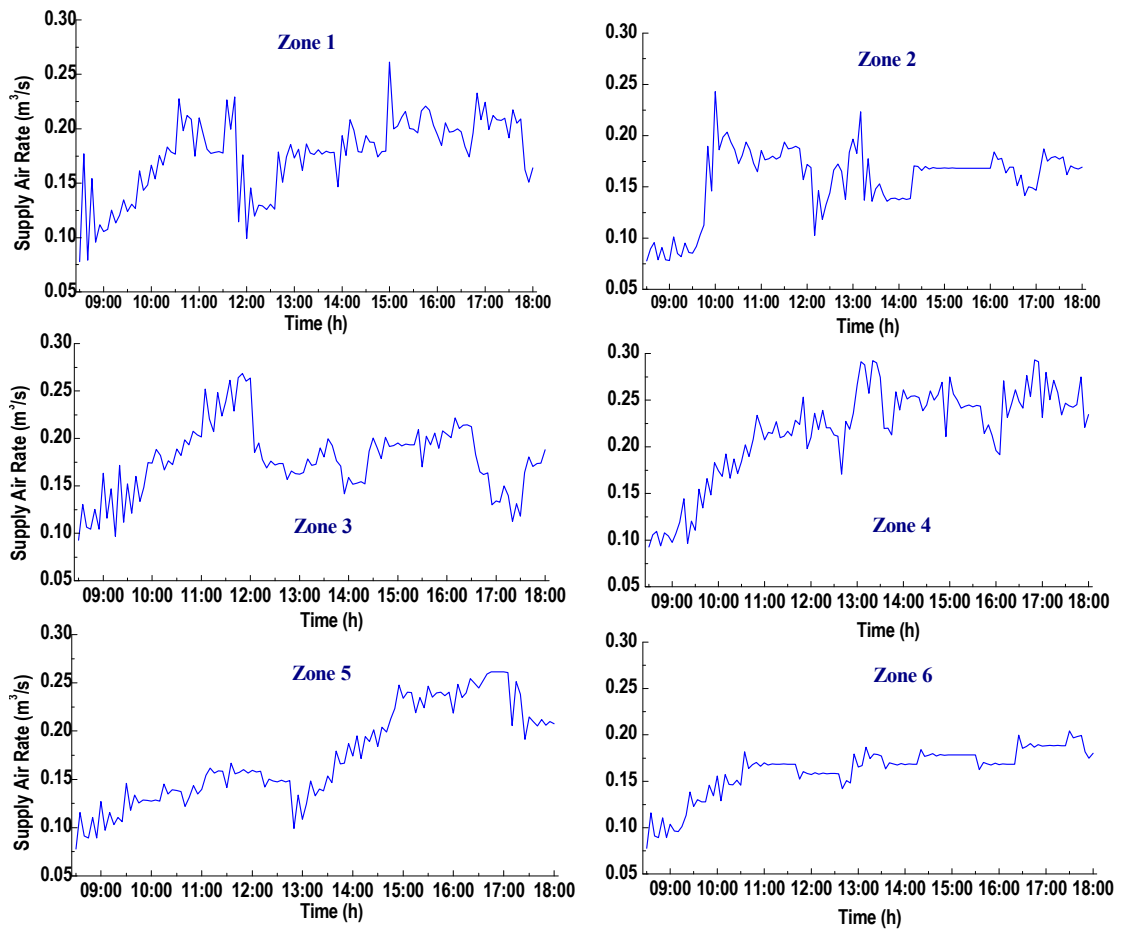

Figure 9. Supply air rate of six zones under Scenario 2. 


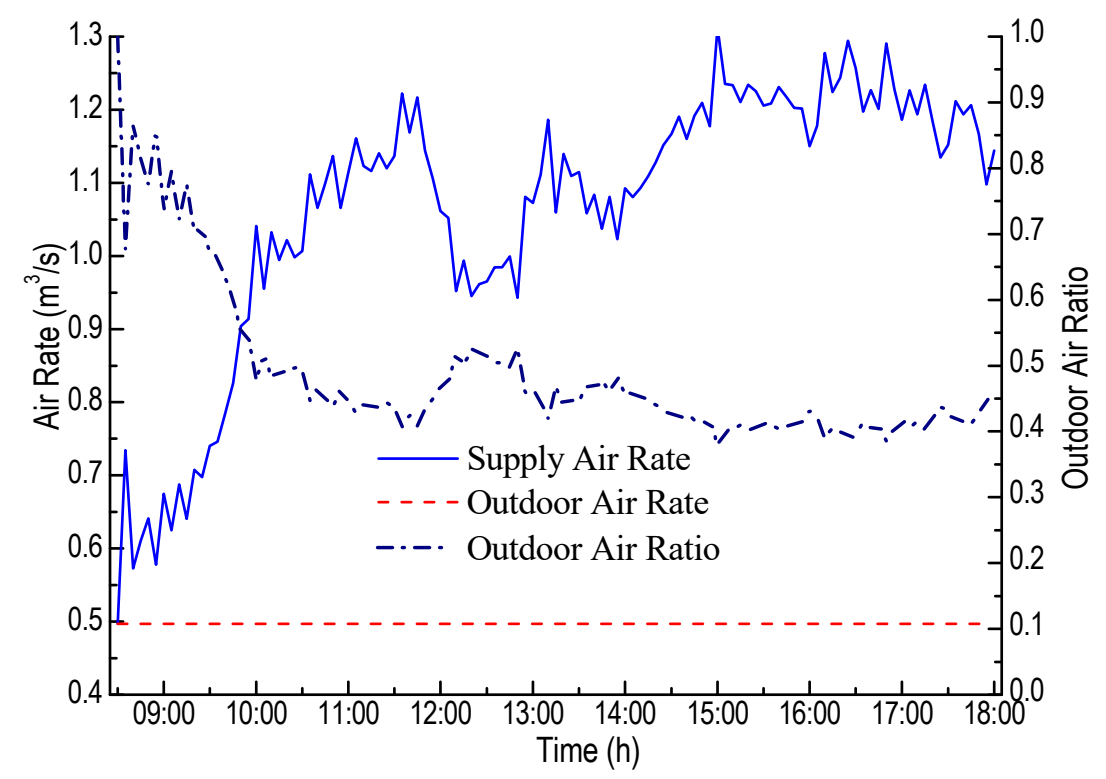

Figure 10. Supply air rate, outdoor air rate, and outdoor air ratio under Scenario 2.

\subsection{Scenario 3: PID Control of Thermal Comfort and Demand-Based Ventilation with Wi-Fi-Enabled Occupancy}

Different from the fixed outdoor air ratio and design outdoor airflow rate, the outdoor airflow rate was determined by the occupancy predicted by the Wi-Fi probe. According to gy 3,Strate the thermal zone with the largest number of occupants was selected as the critical zone, and the outdoor airflow rate was determined by the required fresh air of the critical zone. Strategy 3 was applied to the air conditioning system, severing six thermal zones on the platform of OpenModelica. With the Wi-Fi enabled occupancy, the outdoor airflow rate was first determined by Strategy 3. The outdoor airflow rate was input to the OpenModelica model, and the $\mathrm{CO}_{2}$ concentration levels of the six zones were simulated. The $\mathrm{CO}_{2}$ concentration of the six thermal zones was predicted, as shown in Figure 11. The figure shows that the $\mathrm{CO}_{2}$ concentration of the six thermal zones was not over $1000 \mathrm{ppm}$, which indicates that the determined outdoor air volume could effectively ensure the indoor air quality of six zones. Except Zone 2, the $\mathrm{CO}_{2}$ concentration level of the other five zones generally varied from 850 ppm to 1000 ppm. During 13:00 t0 14:00, Zone 2 had the lowest $\mathrm{CO}_{2}$ concentration, which was caused by the large discrepancy of occupants between Zone 2 and the critical zone.

Besides the $\mathrm{CO}_{2}$ concentration of the six zones, indoor air temperature was analyzed as well, as shown in Figure 12. Under Scenario 3, the indoor air temperature could be maintained around the set-point, by effectively controlling the supply air rate. The changing patterns of air temperature for the six zones were similar. From 8:30 to 9:00, there were large variations of air temperature, as the indoor air temperature varied from $23.6^{\circ} \mathrm{C}$ to $24.1^{\circ} \mathrm{C}$. After 9:00, the indoor air temperature had small variations around the set-point (i.e., $T_{\text {set }}=24^{\circ} \mathrm{C}$ ), and the discrepancy between indoor air temperature and the set-point ranged from $-0.1^{\circ} \mathrm{C}$ to $0.1^{\circ} \mathrm{C}$.

The supply air volume under Scenario 3 was simulated, as presented in Figure 13. Compared to the changing patterns of Scenario 1 and 2, the supply air rates of the six zones showed smaller variations during the working period. As the outdoor air volume was determined according to the predicted occupancy profile, the supply air volume of each zone also varied with the occupancy. Meanwhile, the curves of supply air rate for the six zones were similar. At the beginning of the working period, the supply air rate fluctuated. Then the supply air rate for each zone fluctuated around the average value. For example, after 12:00, the supply air rates of Zone 1 and Zone 2 fluctuated around $0.25 \mathrm{~m}^{3} / \mathrm{s}$ and $0.20 \mathrm{~m}^{3} / \mathrm{s}$, respectively. The overall supply air rates of Zone 4, 5, and 6 varied around $0.15 \mathrm{~m}^{3} / \mathrm{s}$.

The supply airflow rate and outdoor airflow rate of the air conditioning systems were simulated as well, as shown in Figure 14. The changing curves of the supply air rate and the outdoor air rate 
were similar, as they both varied with the occupancy profile. Generally, the outdoor air ratio under Scenario 3 was 0.55 .

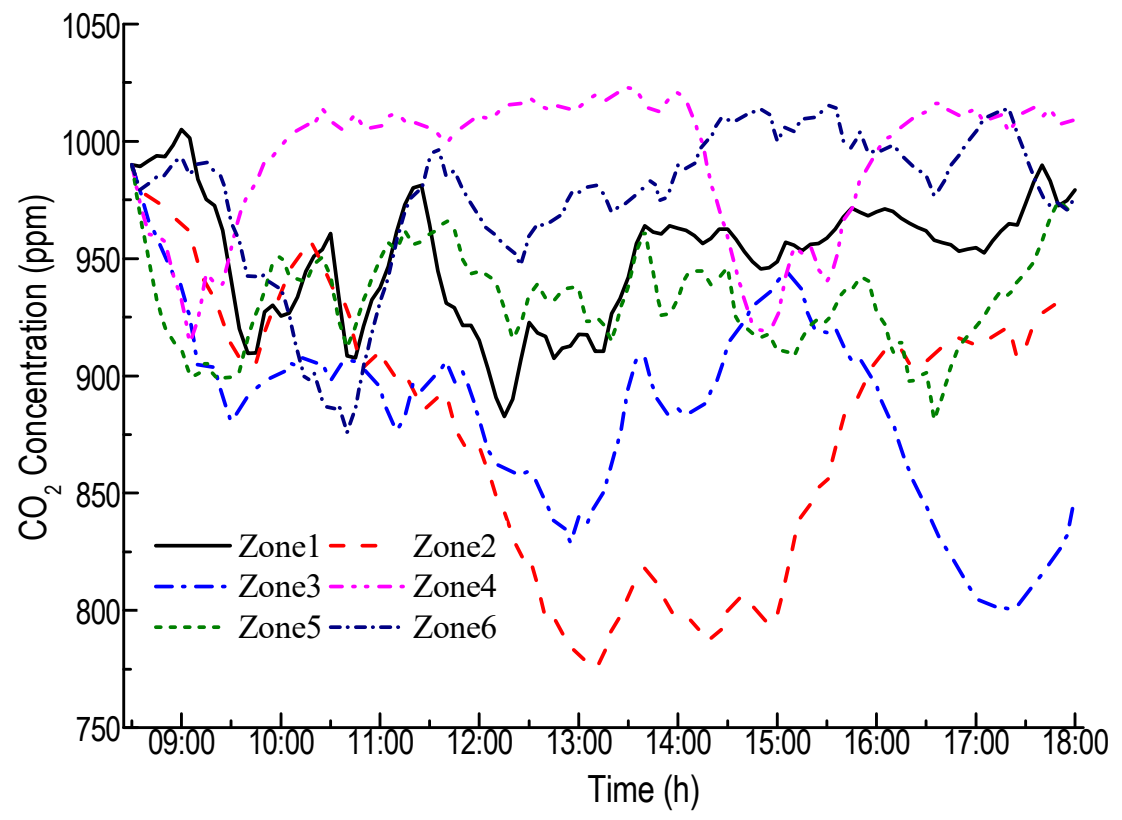

Figure 11. The $\mathrm{CO}_{2}$ concentration of six thermal zones under Scenario 3.
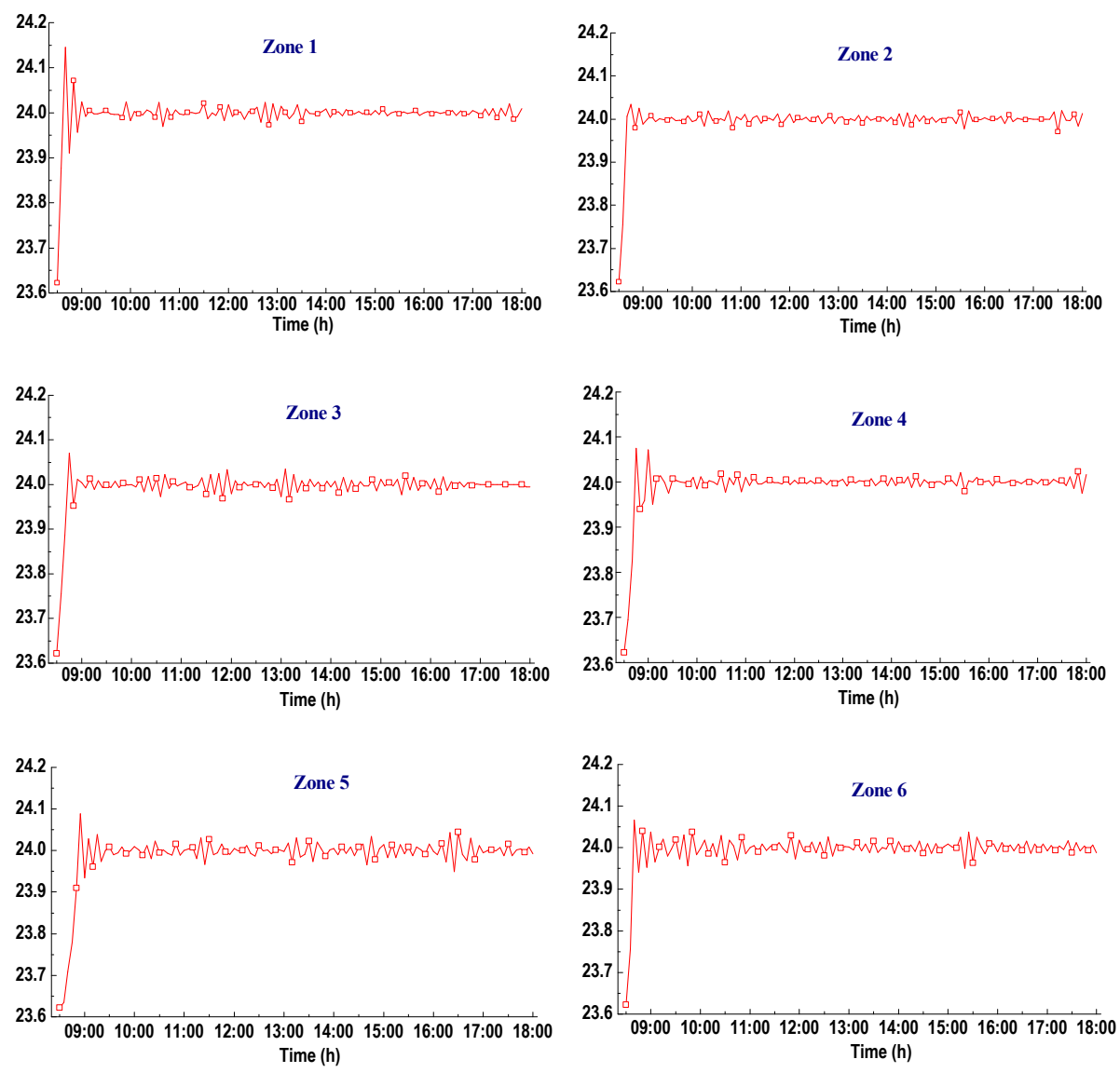

Figure 12. Changing patterns of the indoor air temperature of the six zones, under Scenario 3. 

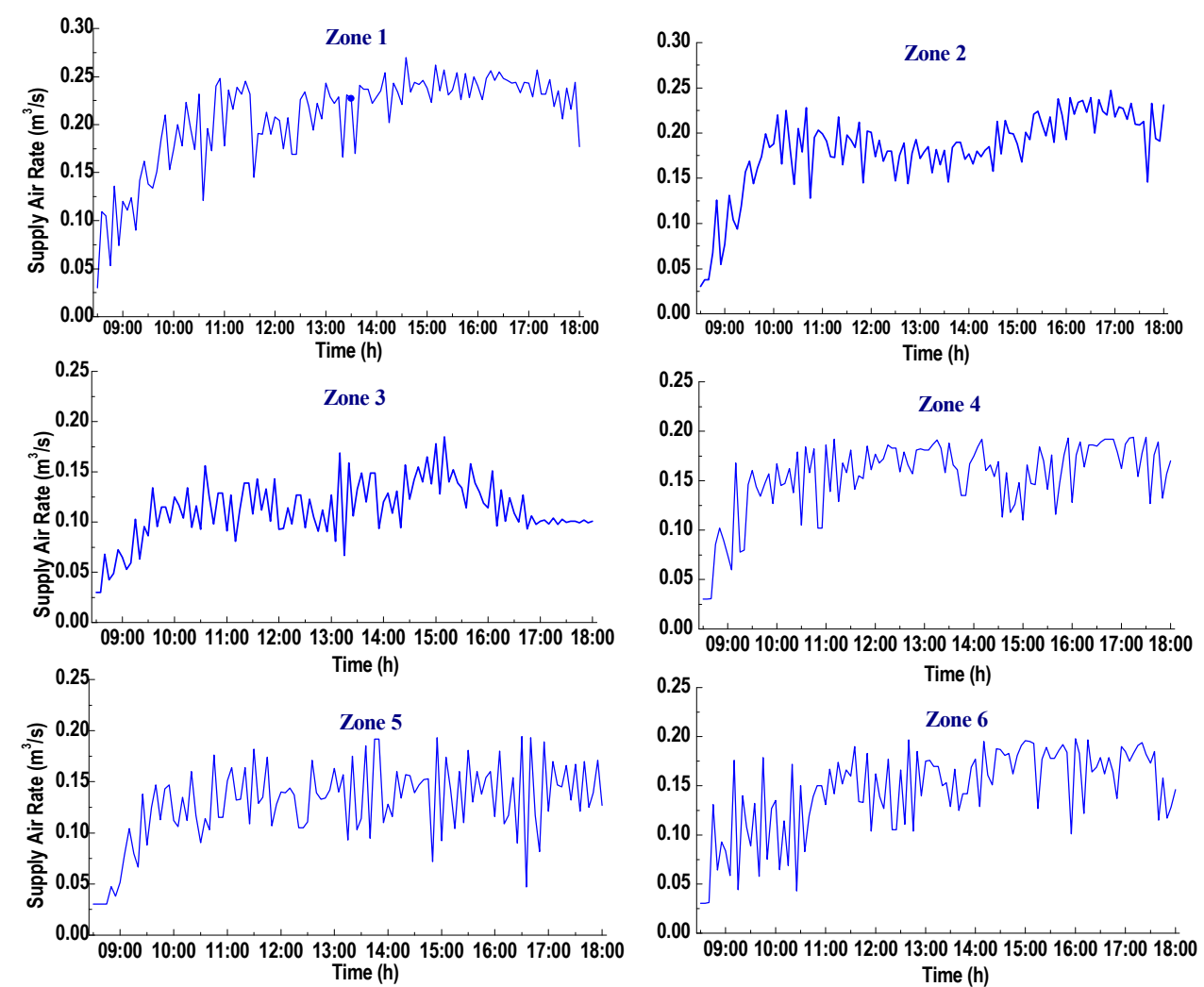

Figure 13. Supply air rate of six zones under Scenario 3.

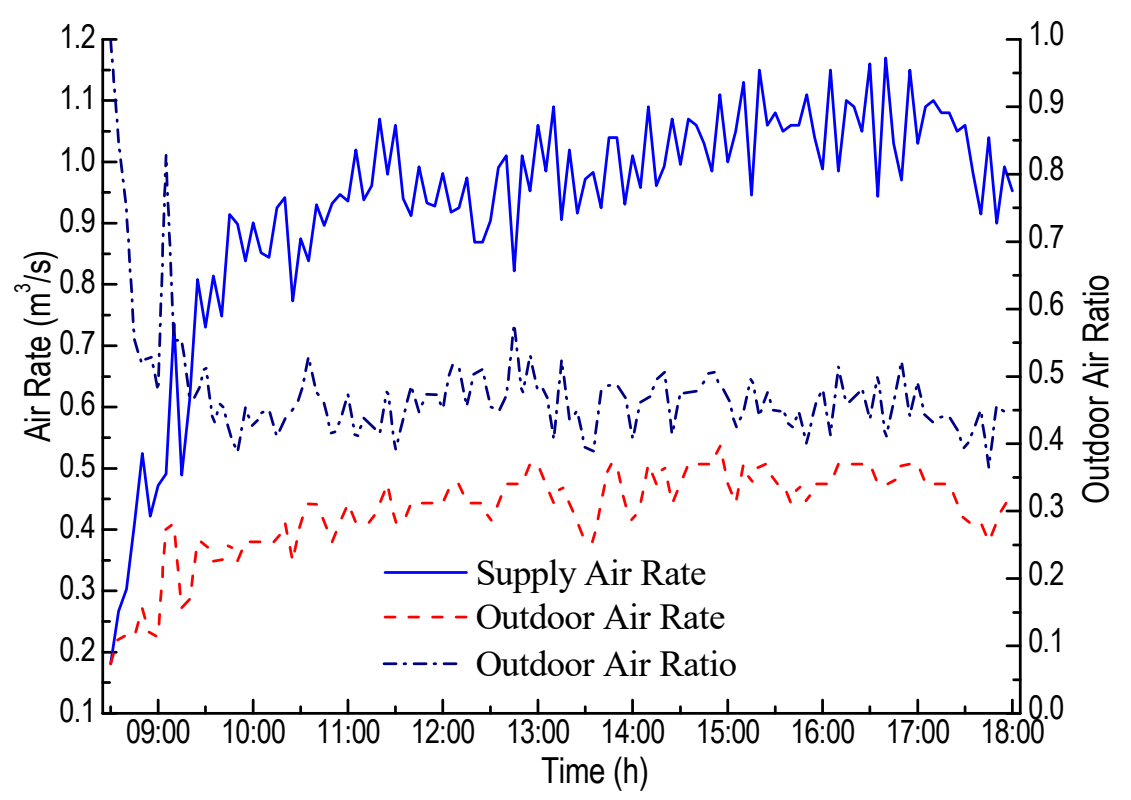

Figure 14. The supply air rate and outdoor air rate of the AC system under Scenario 3.

\subsection{The Energy Use of the Three Scenarios}

Energy use under the three scenarios was analyzed, except for the control performance of indoor air temperature and the $\mathrm{CO}_{2}$ concentration. Energy consumption concerned the power energy of the supply air fan and the outdoor air fan. The rated power of the supply air fan (FCU) was $1100 \mathrm{~W}$, with a rated airflow rate of $5000 \mathrm{~m}^{3} / \mathrm{h}$. The rated power and airflow rate of the fresh air fan (FAU) was $370 \mathrm{~W}$ 
and $2700 \mathrm{~m}^{3} / \mathrm{h}$, respectively. The power energy of the air fan was proportional to the third power of the air volume ratio:

$$
P_{\text {fan }}=P_{\text {fan, rated }} \times\left(\frac{G_{\text {airflow }}}{G_{\text {airflow,rated }}}\right)^{3}
$$

where $P_{\text {fan }}$ is the power energy of the fan, $\mathrm{W} ; P_{\text {fan,rated }}$ is the rated power energy of the fan, $\mathrm{W} ; G_{\text {airflow }}$ is

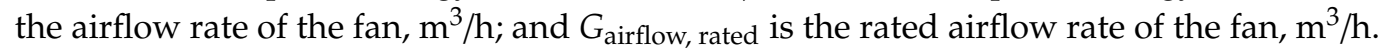

Based on Equation (11), the total power energy of the AC system under the three scenarios was calculated, as presented in Figure 15.

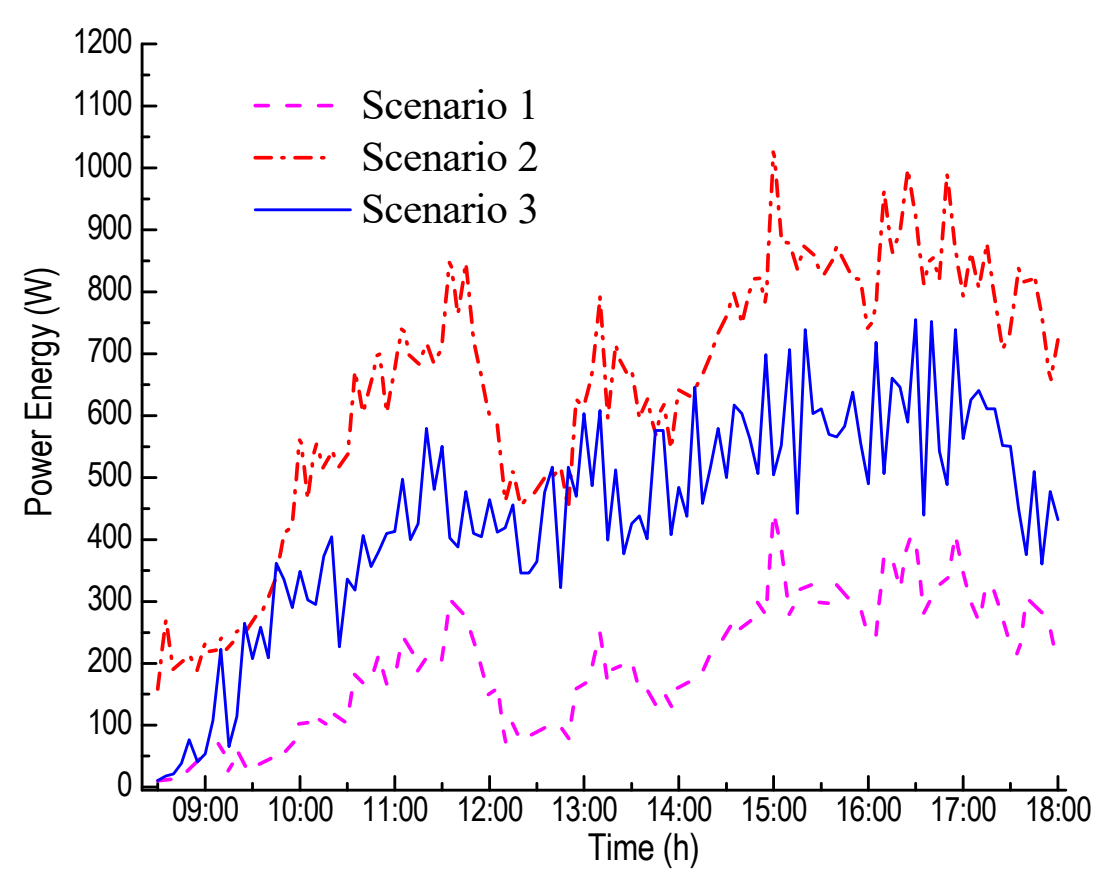

Figure 15. Total power energy of fans under three scenarios.

Through the comparison of the power energy among three scenarios, it was found that the power energy of fans under Scenario 1 was the lowest with the fixed outdoor air fraction. While Scenario 2 consumed the highest power energy with the designed outdoor air rate. The maximum value was $1031 \mathrm{~W}$ at 15:00, when the occupancy was fully loaded. For Scenario 3, the outdoor air was determined according to the predicted occupancy, and thus, the power energy was overall lower than Scenario 2. Since the control method of indoor air temperature was the same for three scenarios, the ventilation scheme decided the discrepancies of power energy. Considering the control performance and power energy of the three control strategies, Strategy 3 had the best performance to maintain thermal comfort and indoor air quality, with acceptable energy usage.

Above all, the comprehensive performance of three control methods for thermal comfort and indoor air quality was discussed. Compared to Strategy 3, Strategy 1 and Strategy 2 were easier implemented in actual applications. The difference between the three strategies lay in the control technique of indoor air quality. By comparing $\mathrm{CO}_{2}$ concentration levels of the six zones under three scenarios (i.e., Figures 3, 7 and 11), it could be deduced that Scenario 1 had the worst control performance of indoor air quality, as the $\mathrm{CO}_{2}$ concentration patterns possess exponential change, and the maximum $\mathrm{CO}_{2}$ concentration level reached $1280 \mathrm{ppm}$. Moreover, the main drawback of Strategy 1 was that outdoor air rate varied with the supply air rate, and low supply air rate induced low outdoor air rate, which caused a poor IAQ for the multi-zone buildings. Under Scenario 2, the $\mathrm{CO}_{2}$ concentration of certain zones was too low, while the other zones were over the set-point of $\mathrm{CO}_{2}$ concentration (i.e., $\mathrm{C}_{\text {set }}=1000 \mathrm{ppm}$ ). The drawback of Strategy 2 was that over-ventilated or under-ventilated cases occurred for the multi-zone buildings. With the predicted occupancy, 
the ventilation scheme was demand-based ventilation, as the outdoor air rate was determined by the predicted occupancy. Under Scenario 3, the indoor air quality of multiple zones could be well maintained with $\mathrm{CO}_{2}$ concentration levels of six zones under the set-point (Figure 11). As for the control performance of the thermal comfort, indoor air temperature of six zones could be well maintained around the set-point (i.e., $T_{s e t}=24^{\circ} \mathrm{C}$ ), as the supply air rate was controlled to ensure the heat balance of the thermal zones (shown in Figures 4, 8 and 12). Besides the performance of thermal comfort and indoor air quality, the energy performance of the three scenarios was compared. The power energy of Scenario 1 was the lowest, while for Scenario 2 the power energy was the highest with the designed outdoor air rate. Compared to Scenario 2, Scenario 3 consumed less power energy, with demand-based ventilation strategy, and the discrepancy between the two scenarios ranged from $14.3 \%$ to $54.9 \%$.

\section{Conclusions}

In this study, the combined control methods of thermal comfort and indoor air quality were investigated to evaluate the control performance and energy use. Three multi-control strategies were applied to a building with six office rooms corresponding to three scenarios. The indoor air temperature and $\mathrm{CO}_{2}$ concentration level of six zones were simulated via OpenModelica platform. Meanwhile, the power energy consumptions of the air conditioning system were compared among three scenarios. Concerning the control performance of thermal comfort, the indoor air temperature of six zones could be well maintained under three scenarios with variable air volume. The temperature differences between indoor air temperature and the set-point ranged from $-0.5^{\circ} \mathrm{C}$ to $0.1^{\circ} \mathrm{C}$, which signified that the VAV could efficiently ensure the thermal comfort of occupants. Through the analysis of $\mathrm{CO}_{2}$ concentration levels, the indoor air quality of the six zones under Scenario 1 was the poorest, as the $\mathrm{CO}_{2}$ concentration was over the set-point during the operation period. The ventilation scheme with fixed outdoor air fraction could not provide enough fresh air to dilute the $\mathrm{CO}_{2}$ generated by occupants. Under Scenario 2, the outdoor air rate was determined as the design outdoor air rate, according to the ASHRAE standard. When the number of occupants was more than the design number, the $\mathrm{CO}_{2}$ concentration level was over $1000 \mathrm{ppm}$. The $\mathrm{CO}_{2}$ concentration of the six zones ranged from $350 \mathrm{ppm}$ to $1000 \mathrm{ppm}$ between 8:30 to 12:00, with fewer occupants inside the building. Different from Scenario 2, the outdoor air rate dynamically varied with the number of occupants. Based on the predicted occupancy with the Wi-Fi probe, the ventilation scheme was demand-based outdoor air rate, under Scenario 3. The $\mathrm{CO}_{2}$ concentration of the six zones could be maintained around $1000 \mathrm{ppm}$. Additionally, the total power energy of the three scenarios was analyzed. Although the power energy of Scenario 1 was the lowest, the control method could not provide acceptable indoor air quality for occupants. While the control method of Scenario 2 consumed the highest power energy, this control method might induce over ventilation, due to the use of a design outdoor air rate. Scenario 3 required less power energy than Scenario 2 to maintain acceptable indoor air quality for the six zones, as the ventilation method was demand-based ventilation. Therefore, Strategy 3 (i.e., PID control of thermal comfort and demand-based ventilation) possessed the best performance on controlling thermal comfort and indoor air quality.

Author Contributions: Conceptualization, W.W. and X.S.; Methodology, W.W. and X.S.; Software, X.S.; Validation, X.S. and Y.J.; Formal analysis, W.W. and X.S.; Investigation, S.A.H.; Resources, X.S. and C.W.; Writing-original draft preparation, X.S. and W.W.; Writing-review and editing, W.W. and X.S. All authors have read and agreed to the published version of the manuscript.

Funding: The work described in this paper was sponsored by the Natural Science Foundation of Jiangsu Province (\#BK20190362), and was also supported by National Key R\&D Program of China (\#2019YFD1100903). Any opinions, findings, conclusions, or recommendations expressed in this paper are those of the authors and do not necessarily reflect the views of the NSFC. The work was also supported by Research Grant Council of Hong Kong Special Administrative Region, China (RGC \#11209518).

Conflicts of Interest: The authors declare no conflict of interest. 


\section{References}

1. Pérez-Lombard, L.; Ortiz, J.; Pout, C. A review on buildings energy consumption information. Energy Build. 2008, 40, 394-398. [CrossRef]

2. Lymperopoulos, G.; Ioannou, P. Building Temperature Regulation in a Multi-Zone HVAC System using Distributed Adaptive Control. Energy Build. 2020, 215, 109825. [CrossRef]

3. Antoniadou, P.; Papadopoulos, A.M. Occupants' thermal comfort: State of the art and the prospects of personalized assessment in office buildings. Energy Build. 2007, 153, 136-149. [CrossRef]

4. Englund, J.S.; Cehlin, M.; Akander, J.; Moshfegh, B. Measured and Simulated Energy Use in a Secondary School Building in Sweden-A Case Study of Validation, Airing, and Occupancy Behavior. Energies 2020, 13, 2325. [CrossRef]

5. Silva, M.F.; Maas, S.; De Souza, H.A.; Gomes, A.P. Post-occupancy evaluation of residential buildings in Luxembourg with centralized and decentralized ventilation systems, focusing on indoor air quality (IAQ). Assessment by questionnaires and physical measurements. Energy Build. 2017, 148, 119-127. [CrossRef]

6. Lin, Z.; Chow, T.T.; Fong, K.F.; Tsang, C.F.; Wang, Q. Comparison of performances of displacement and mixing ventilations. Part II: Indoor air quality. Inter. J. Refrig. 2005, 28, 288-305. [CrossRef]

7. Kim, J.; Song, D.; Kim, S.; Park, S.; Choi, Y.; Lim, H. Energy-Saving Potential of Extending Temperature Set-Points in a VRF Air-Conditioned Building. Energies 2020, 13, 2160. [CrossRef]

8. Mathews, E.H.; Arndt, D.C.; Piani, C.B.; Van Heerden, E. Developing cost efficient control strategies to ensure optimal energy use and sufficient indoor comfort. Appl. Energy 2000, 66, 135-159. [CrossRef]

9. Dounis, A.I.; Caraiscos, C. Advanced control systems engineering for energy and comfort management in a building environment-A review. Renew. Sustain. Energy Rev. 2009, 13, 1246-1261. [CrossRef]

10. Koulani, C.; Hviid, C.; Terkildsen, S. Optimized damper control of pressure and airflow in ventilation systems. In Proceedings of the 10th Nordic Symposium on Building Physics, Lund, Sweden, 15-19 June 2014; pp. 15-19.

11. Wang, S.; Xu, X. Optimal and robust control of outdoor ventilation airflow rate for improving energy efficiency and IAQ. Build. Environ. 2004, 39, 763-773. [CrossRef]

12. Shan, X.; Xu, W.; Lee, Y.K.; Lu, W.Z. Evaluation of thermal environment by coupling CFD analysis and wireless-sensor measurements of a full-scale room with cooling system. Sustain. Cities Soc. 2019, 45, 395-405. [CrossRef]

13. Shan, X.; Luo, N.; Sun, K.; Hong, T.; Lee, Y.K.; Lu, W.Z. Coupling CFD and Building Energy Modelling to Optimize the Operation of a Large Open Office Space for Occupant Comfort. Sustain. Cities Soc. 2020, 60, 102257. [CrossRef]

14. Yao, Y.; Lian, Z.; Liu, W.; Hou, Z.; Wu, M. Evaluation program for the energy-saving of variable-air-volume systems. Energy Build. 2007, 39, 558-568. [CrossRef]

15. Okochi, G.S.; Yao, Y. A review of recent developments and technological advancements of variable-air-volume (VAV) air-conditioning systems. Renew. Sustain. Energy Rev. 2016, 59, 784-817. [CrossRef]

16. Zhang, X.; Wang, R.; Xing, J. Optimization control method of VAV air conditioning system. In Proceedings of the 12th World Congress on Intelligent Control and Automation (WCICA), Guilin, China, 12-15 June 2016; pp. 1105-1110.

17. Tukur, A.; Hallinan, K.P. Statistically informed static pressure control in multiple-zone VAV systems. Energy Build. 2017, 135, 244-252. [CrossRef]

18. Engdahl, F.; Johansson, D. Optimal supply air temperature with respect to energy use in a variable air volume system. Energy Build. 2004, 36, 205-218. [CrossRef]

19. Dong, J.; Winstead, C.; Nutaro, J.; Kuruganti, T. Occupancy-based HVAC control with short-term occupancy prediction algorithms for energy-efficient buildings. Energies 2018, 11, 2427. [CrossRef]

20. Yuan, J.; Chen, Z.; Zhong, L.; Wang, B. Indoor air quality management based on fuzzy risk assessment and its case study. Sustain. Cities Soc. 2019, 50, 101654. [CrossRef]

21. Griffiths, M.; Eftekhari, M. Control of $\mathrm{CO}_{2}$ in a naturally ventilated classroom. Energy Build. 2008, 40, 556-560. [CrossRef]

22. ASHRAE Standard. 62.1, 2019. Standard 62.1-2019 Ventilation for Acceptable Indoor Air Quality; American Society of Heating, Refrigerating and Air Conditioning Engineers: Atlanta, GA, USA, 2019. 
23. Chao, C.Y.H.; Hu, J.S. Development of a dual-mode demand control ventilation strategy for indoor air quality control and energy saving. Build. Environ. 2004, 39, 385-397. [CrossRef]

24. Kumar, P.; Martani, C.; Morawska, L.; Norford, L.; Choudhary, R.; Bell, M.; Leach, M. Indoor air quality and energy management through real-time sensing in commercial buildings. Energy Build. 2016, 111, 145-153. [CrossRef]

25. Lu, T.; Lü, X.; Viljanen, M. A novel and dynamic demand-controlled ventilation strategy for $\mathrm{CO}_{2}$ control and energy saving in buildings. Energy Build. 2011, 43, 2499-2508. [CrossRef]

26. Nassif, N.; Kajl, S.; Sabourin, R. Ventilation control strategy using the supply $\mathrm{CO}_{2}$ concentration setpoint. HVAC R Res. 2005, 11, 239-262. [CrossRef]

27. Wang, W.; Wang, J.; Chen, J.; Huang, G.; Guo, X. Multi-zone outdoor air coordination through Wi-Fi probe-based occupancy sensing. Energy Build. 2018, 159, 495-507. [CrossRef]

28. ASHRAE Standard. Standard 55-2017 Thermal Environmental Conditions for Human Occupancy; ASHRAE: Atlanta, GA, USA, 2017.

29. Karunakaran, R.; Iniyan, S.; Goic, R. Energy efficient fuzzy based combined variable refrigerant volume and variable air volume air conditioning system for buildings. Appl. Energy 2010, 87, 1158-1175. [CrossRef]

30. Pang, X.; Piette, M.A.; Zhou, N. Characterizing variations in variable air volume system controls. Energy Build. 2017, 135, 166-175. [CrossRef]

31. Zhao, T.; Hua, P.; Dai, W.; Zhang, J.; Ma, L. An optimal control method for discrete variable outdoor air volume setpoint determination in variable air volume systems. Build. Environ. 2020, 167, 106444. [CrossRef]

32. Fritzson, P.; Engelson, V. Modelica-A unified object-oriented language for system modeling and simulation. In Proceedings of the European Conference on Object-Oriented Programming, Brussels, Belgium, 20-24 July 1998; pp. 67-90.

33. Fritzson, P. Modelica-A cyber-physical modeling language and the OpenModelica environment. In Proceedings of the 7th International Wireless Communications and Mobile Computing Conference, Istanbul, Turkey, 4-8 July 2011; pp. 1648-1653.

34. Felgner, F.; Merz, R.; Litz, L. Modular modelling of thermal building behavior using Modelica. Math. Comput. Model. Dyn. Syst. 2006, 12, 35-49. [CrossRef]

35. Li, P.; Li, Y.; Seem, J.E.; Qiao, H.; Li, X.; Winkler, J. Recent advances in dynamic modeling of HVAC equipment. Part 2: Modelica-based modeling. HVAC R Res. 2014, 20, 150-161. [CrossRef]

36. Wetter, M. A Modelica-Based Model Library for Building Energy and Control Systems; Lawrence Berkeley National Laboratory: Berkeley, CA, USA, July 2009.

37. Wetter, M.; Zuo, W.; Nouidui, T.S.; Pang, X. Modelica buildings library. J. Build. Perform. Simul. 2014, 7, 253-270. [CrossRef]

38. Wang, W.; Chen, J.; Hong, T.; Zhu, N. Occupancy prediction through Markov based feedback recurrent neural network (M-FRNN) algorithm with Wi-Fi probe technology. Build. Environ. 2018, 138, 160-170. [CrossRef] 